\title{
An Introduction to Marxist Innovation Education Exemplified in the Automatic Culture of Cordyceps Militaris
}

\author{
Luo Qing
}

\begin{abstract}
The method of systematic contradiction is applied to study Marxist innovation education. Marxist innovation theory provides guidelines for the system-constructing of the automatic culture of Cordyceps militaris, which exemplified the three states of Marxist innovation education. Its principle is that the practice of innovation education decides the theory of innovation education. Our innovation practice of the Cordyceps militaris automatic culture exemplified the innovation spirit education, innovation ability education and innovation resources education. And what inspired by the practice is to make Marxist innovation education part of systematic moral education. But the structural research of its innovation quality system is still to be furthered.
\end{abstract}

Index Terms-Marxism, innovation theory, Marxist innovation education, innovation resources, systematic contradiction.

\section{INTRODUCTION}

Knowledge economy brings us a new era: being a kind of intellectual economy, takes human capital as the leading factor; being innovative economy, takes innovation quality as the leading factor. Innovation quality is decisive to human capital, and can be nurtured. Innovation theories can be concluded into two species: Marxist innovation theory and non-Marxist innovation theory. With the accelerating of knowledge economy, the non-Marxist innovation theory shows a trend of being in lack of resources to offer inspiration, method and value for innovation education.

Here we turn to Marxist innovation theory for help, because it is well equipped with the philosophy of materialist dialectics, such as its application helped to manifest that innovation resource is produced through the dialectic interaction of subjective resource and objective resource of innovation. And Marxist innovation theory reveals the essence of innovation: it is benefits driven creative practice that increased total benefits in deed[1]. The total benefits are by no means restricted in economy or financial field, but content not only the material things such as profit or interests, but also the spiritual field such as mind peace and harmony. The importance can never be neglected is to build a

Manuscript received July 31, 2016; revised October 23, 2016. This work was supported in part by Zhaoqing University. The financial support comes from a Youth Project: Expert System Development for the Automatic Culture of Cordyceps Militaris, under Grant NO.201542, one scientific research fund project of Zhaoqing University.

Luo Qing is with the Teaching Department of Ideological and Political Theory, Zhaoqing University, Yingbin Road, Zhaoqing City, Guangdong 526061, China (e-mail: 457545867@qq.com). harmonious relationship between teacher and students, and it fills well into Marxist innovation education. With its systematic strength, Marxist innovation theory can provide new and wholesome frame work for innovation education in constructing Learning Systems Platforms, especially for Web-based Learning. This may eradicate the alienation problems brought forth by capitalist education. Besides, by solving the alienation problems in the field of innovation education, Non-Marxist or anti-Marxist is kept in the subordinate position to some extent.

\section{MARXist INNOVATION EdUCATION EXEMPLIFIED IN THE COMBINATION OF THEORY WITH PRACTICE}

\section{A. Three States in One}

To Marxists, it is an essential principle that we must combine theory with practice. The practice of innovation education is decisive to the theory of innovation education, speaking in details, provides requirements for the innovation education theory, gives birth to it, and tests it, just as practice does to theory. Marxist innovation education can be well exemplified in our innovation education practice of the automatic culture of Cordyceps militaris. Because Marxist innovation theory provides us a new worldview of things, it contests that everything in its condition has three forms or states, functions differently to manifest one essence. The three states embodied in the innovation education respectively as the three layers of the education of innovation spirit, of the education of innovation ability, and of the education of innovation resource. So in the selection of a proper project for example to practice Marxist innovation education, the three layers must be conducted.

\section{B. The Education of Innovation Spirit Exemplified}

Chairman Mao Zedong guided us to make the past serve the present and foreign things serve China. In terms of the education of innovation spirit, Marxist innovation theory asks to adapt ancient forms for present-day use; and to make the past things serve our present-day needs. And it is Marxist innovation theory inspired us to do research, by convincing us to believe everywhere is the place for creation, every day is the time for creation, everyone is the person for creation. To innovate, China is the place, now is the time, we youngsters are the person. This makes us equipped with innovation awareness. The Cordyceps is then found out the very past things. It is Chinese precious tonic herb, known as "the Millennium Chinese medicine", the reputation of "the king of medicine", and is considered better in restoring health 
than ginseng or antler by accomplishing a balance between yin and yang, in the sense of traditional Chinese medicine. All Cordyceps species are endoparasitoids, parasitic mainlyon insects and other arthropods (they are thus entomopathogenic fungi); a few are parasitic on other fungi. Until recently, the best known species of the genus was Cordyceps sinensis [2]. The Cordyceps is ancient, because it is a kind of eumycota, which comes to exist earlier than any specie of human being more than hundred thousands of years But the Cordyceps is a rare and endangered species, and is heading for extinction due to pollution and over-digging. It is obviously difficult to rejuvenate the Cordyceps, while the colony of bacteria is even hard to find. Here the innovation awareness makes us see that there is no other area offers richer opportunities for successful innovation than the unexpected traditional area.

But the innovation awareness alone is not enough for our laboratories carried on studying till the Cordyceps culture is obtained. Only by the combined action of innovation awareness and innovation willpower, can innovation get its spiritual dynamic to start and to continue till success. Innovation awareness and innovation willpower form the unity of opposites of the innovation spirit, which through interaction of these two opposites produces nonintellectual factors[3]. Marxist innovation theory define capitalism in terms of resource use and control, but more in terms of alienation because of exploitation. The alienation of labor makes work in company kind of torture, and inspired us to do the culture of Cordyceps militaris at home and by automation To terminate the alienation of labor in order to liberate human being is a honorable purpose, provided us innovation willpower to persist in innovating all kinds of methods till we realized the automatic culture of Cordyceps militaris. Imagine how wonderful it is to be liberated from nine-to-five jobs, when the automation is accomplished, we can work at home, can even work while traveling away from home, because the Cordyceps militaris is well controlled to grow automatically no matter wherever you are.

The above exemplified that the innovation spirit as an opposites unity of innovation awareness and innovation willpower, makes us select and carry on the project purposefully, because it equips us with the nonintellectual factors of innovation quality. However by the spirit alone, it is not enough to accomplish the automatic culture of Cordyceps militaris, the ability of innovation is required to obtain the intellectual factors of innovation, which makes us know how, can do and complete innovation. The Marxist innovation theory should be made full use of, to improve innovation ability, so that we can accomplish the automatic culture of Cordyceps militaris.

\section{The Education of Innovation Ability Exemplified}

Marxist innovation theory divides the quality facts of innovator into nonintellectual factors and intellectual factors. The former produced by the interaction of innovation awareness and innovation willpower, make us to innovate and persist in innovating; the latter though based on motive power from the innovation spirit, it could only be obtained through innovation ability directly. The innovation ability is an opposites unity of innovation methods and innovation resources. In our concrete practice, it is by applying Marxist innovation theory to improve innovation ability, especially the ability of system-constructing that ensured us obtain, create and integrate necessary intellectual factors of innovation to embrace success. Innovation is viewed by Marxism a systematic contradiction, composed by the contradictory interaction of scientific and technological innovation, economic innovation, politic innovation, cultural innovation and social innovation[4]. This provided us with efficient thinking model, conducting standards and regulations in the system-constructing of the automatic culture of Cordyceps militaris.

Firstly, the "systematic contradiction" point of view inspired us that the automation is also a systematic contradiction, and by applying Marxist innovation method of combination, we combined the science of Cordyceps culture with automatic technology in creating the systematic contradiction of automation. To explain it in details may help to understand. On one side, the Cordyceps culture science shows, that in environment, the Cordyceps is restricted by two major factors: light and temperature. In terms of light, it needs 14 hours sunshine everyday, and the intensity of illumination must be no less than 1000 lumen (LM) at the same time. In terms of temperature, it needs sharp temperature change, but with the extremes of 15 centigrade degree at night and 30 centigrade degree in day time. On the other side, the automatic technology can control light and temperature easily, detecting temperature with temperature sensor and adjusting temperature with refrigeration according to the restricted extremes set in small-core memory. So directed by combination, the method offered by Marxist innovation theory, we joined these two fields to create a new systematic contradiction that has its own systematic factors, structure and borderline to function automatically. However in practice, we did kind of separation before the combination, such as knowing Cordyceps is some kind of bacteriostat, we isolated from the spore of Cordyceps that is the most dynamic for the culture of Cordyceps militaris. Thus, our system-constructing, which mainly belongs to the scientific and technological innovation, brings more convenience by the combination based on separation.

Secondly, the systematic contradiction is constructed considering Marxist theory of economic innovation, politic innovation, cultural innovation and social innovation. Marxist theory of economic innovation requires innovation to produce more interests by better cooperation, literally to earn more money than before in this capital-manipulated modern time. So in the system-constructing of the automatic culture of Cordyceps militaris, we considered reducing the costs of time, energy and equipment respectively. To reduce the cost for example, the temperature range is set at 18 centigrade degree at night and 25 centigrade degree in day time, the intensity of illumination is set at 1000 lumen (LM) for the best environment condition. And other interrelated necessities such as the small-core memory, are all set to the best function in terms of system inner factors, according to the latest experiments. Marxist theory of politic innovation requires innovation to accelerate democratization, that is to get more people engaged and share. So in the system-constructing, we considered optimizing the automatic 
system for working at home, such as minimized the equipment by using refrigeration chip made of semiconductor. Image 1 in the following is the refrigeration chip, which is only 25 square centimeters taking less space than traditional refrigerator very much. The whole work can be operated properly on your kitchen table, can get anyone engaged and share. Marxist theory of cultural innovation requires to enhance the sense of identity, meanly to make you feel spiritually agreeable and satisfied. So in the system-constructing, we managed to make it an open system, easy to use for any customers of different backgrounds. Image 2 in the following, is an ordinary computer fan familiar to youngsters nowadays, can be assembled easily with the refrigeration chip radiator to make a suitable radiator for heat dissipating. In making a presentable interface, the automatic culture platform is simplified into a plate made of bronze, as the image 2, which is of good conductivity for heat to be transformed from culture medium inside the vessel easily, and is open for vessel of any shape to be put on. And our design controls the temperature change by contact and heat radiation that is not restricted by the material quality of vessel, then has obvious culture adaptive faculty for international marketing. Last but not least, Marxist theory of social innovation requires to improve harmony, in its broadest meaning, is to build a harmonious international society that each individual enjoys equal relation supported by financial independence. This gives us spark to create useful and affordable means of production with automatic arrangement for everyone. So in the system-constructing, hygienic plastic syringe is used to package the seeds of liquid culture that can be directly sprayed into the vessel with a simple injection. And the mass of rice or wheat is common food cooked in home worldwide, can serve as our culture medium conveniently to be prepared in the vessel. When its temperature is reduced to no more higher than 25 centigrade degree in the vessel, the Cordyceps militaris seeds of liquid culture is sprayed inside with the syringe, which is also its package. This makes each normal individual capable of growing Cordyceps militaris at home. In our experiment, the rice cocked culture medium is thoroughly permeated with Cordyceps mycelium, and orange flower blooms, after it is sterilized properly by liquid culture seeds sprayed. Besides, you can watch the growing and its color change: from nothing to some white, to yellowish spore, and to orange bloom. You can appreciate while it is blooming to your appetite, and is is free of wash, presenting as image 3 .

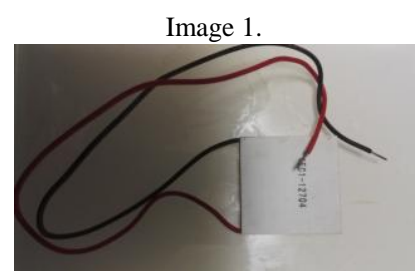

Image 3 .

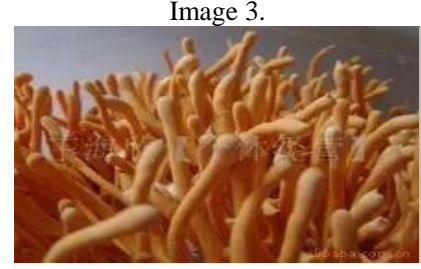

Image 5.
Image 2 .

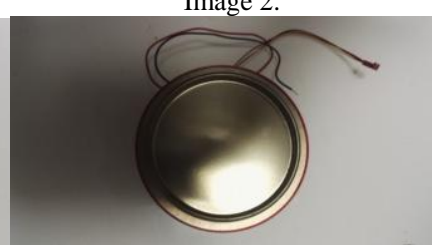

Image 4.

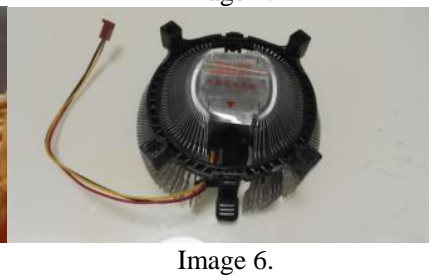

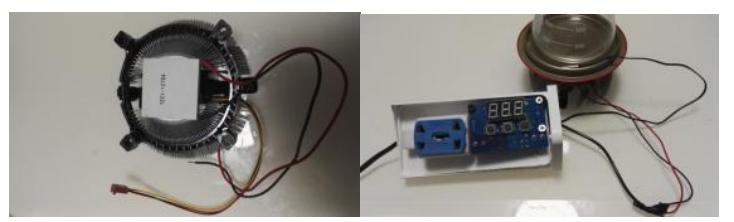

\section{The Education of Innovation Resources Exemplified}

Karl Marx has written that, modern industry makes science a productive force distinct from labor and presses it into the service of capital. But that was as early as 1867 , the role of science and technology in the knowledge economy differs obviously from that in the industrial economy with which we have developed economic innovation theory. So far, the materialist dialectics of Marx has been used to analyze innovation resources, and develop out two categories: objective innovation resources and subjective innovation resources, which compose the third layer of innovation. Among which, the subjective innovation resources function principal aspect, include the resources of knowledge and the resources of management, which through their inner dialectic interaction, produce all subjective innovation resources. Considering that knowledge exists ahead of management, and the management resources is turned into innovation resources only when combined with innovation knowledge, we began the system-constructing of Cordyceps militaris automatic culture by searching internet (mainly baidu.com) for necessary knowledge, to grasp the principle aspect first, since all innovations relay on knowledge resource that is revered by Marxists. Knowledge as the subjective innovation resources, by Marxist material dialectics, can be divided into the resources of science and technology, and the resources of other knowledge.

According to professor Ni Xiao Jian, the knowledge embodied mainly as science and technology, which is characterized by huge time span. Because it takes a long time for new science knowledge to emerge, and for its becoming applicable to technology. Being directed against this, we got the resources in need swiftly by following the mass line provided by Marxist innovation theory. We consulted first computer engineers for useful opinions, such as the computer fan runs at about 5 volts with flexibility, and is still in the same volt range of the semiconductor refrigeration chip of the same size, as showed in the above image 4 . Then, through a chemistry teacher, we were assured of that it is safe to use hygienic plastic syringe as the package, which was specifically showed how to inject into the culture vessel by a nurse friend consequently. And then, through the investigating in taobao(HTTP://WWW.taobao.com/), we were recommended by seller a good way to assemble, such as the fan is fixed with the semiconductor refrigeration chip by a glue of high conductivity used for the heat dissipating, presented just as the above image 5. Meanwhile, common sense and market demand as the resources of other knowledge, helped to add a bronze plate of proper size, as you can observe in the above image 6 . When all the knowledge needed is available and assembled, the process of our system-constructing of the automatic culture of Cordyceps militaris is completed.

However, the innovation resources produced by practicing the mass line is by on means confined to the knowledge of science or technology. The mass line has also innovative function for management. It makes general management be 
turned into innovation management. And it is well known that, Management is the new technology (rather than any specific new science or invention) that is making the American economy into an entrepreneurial society[5]. Here we can see that the management can also be decisive to innovation resources or economy, from certain viewpoint. In most cases when innovation is aborted halfway, it is because of the lack of necessary management. There is no doubt, that high tech in the form of computer, has tremendous beneficial influence on means of human society life and work. So we turned to a computer software engineer for innovation management, because he wrote a clean air drying system powered by solar energy, as the following image 7 , which is borrowed as the management software system to monitor our automatic culture system. The image 7 also shows that the system keeps an account of the curve chart of temperature and humidity respectively, and it monitors well the switching mode power supply of refrigeration chip, humidifier and light, etc. The computer aided management ensured us to handle unexpected new problems and to improve the culture quality of Cordyceps militaris automatically.

What's more, market-oriented innovation was tried in our practice, because Marxist innovation theory emphasizes the focus on the market, taking it a decisive factor. By applying the automatic culture of Cordyceps militaris to the market of intellectual property right, we cooperated with the Life Sciences college of Zhaoqing University for current knowledge of molecular biology to develop the entomopathogenic fungi of Cordyceps militaris. Image 8 in the following is our experimental result of comparison experiments for your reference. The Cordyceps militaris is found functionally similar to Cordyceps sinensis, in containing cordycepin, cordycepic acid, polysaccharides, trace elements, varieties of essential amino acids and vitamins. Among which, the cordycepin have some anticancer activity in preliminary animal studies. As the Cordyceps fungus is becoming rare and worth higher and higher price, our automatic culture of Cordyceps militaris is becoming popular.

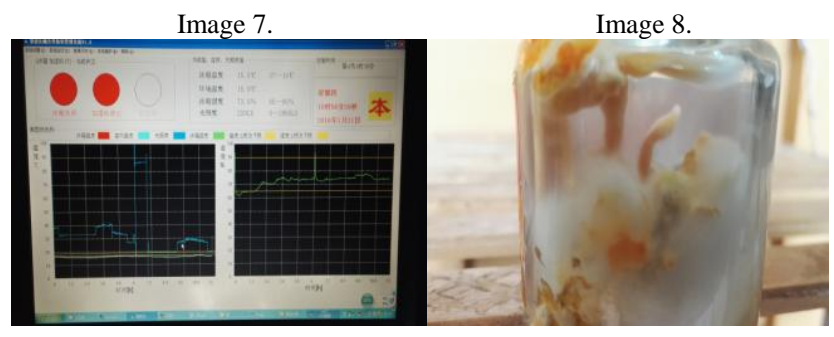

\section{MARXIST INNOVATION EDUCATION EXEMPLIFIED A SYSTEMATIC CONTRADICTION}

There is no uniform model of innovation education till now, but we can innovate one dialectic model for it, by which the basic innovation quality system will be easily defined. Our system-constructing of the automatic culture system of Cordyceps militaris explained explicitly that Marxist innovation education has the contradictory two aspects of Marxist innovation practice education and Marxist innovation theory education. The former exists first, plays the decisive role, then is the principle aspect. Innovation education should improve innovation quality.
In terms of systematic factors, Marxist innovation education has innovation quality, innovation spirit, innovation awareness, innovation willpower, innovation ability, innovation method, innovation resources, objective innovation resources, subjective innovation resources, innovation knowledge and innovation management.

In terms of systematic structure, as it shows in the following Fig. 1, each upper system factor is composed by the two aspects' interaction of lower system factors, and the former functions the principle aspect, the latter functions the secondary aspect as a wife in a couple, can born new contradict. For example, if our system-constructing were in lack of knowledge, the innovation management of the automatic culture system of Cordyceps militaris must be short of "software", and it is the prerequisite knowledge that makes management innovative, so the knowledge is decisive subjective resources of innovation, functions the principle aspect generally speaking. Though usually the innovation management functions the secondary aspect, it can also be decisive in certain cases, such as when our system-constructing was almost aborted halfway in lack of monitor software.

In terms of systematic function, the systematic contradiction exemplified provides us with some kind of model for innovation education, can be directive in establishing the evaluation system for innovation quality.

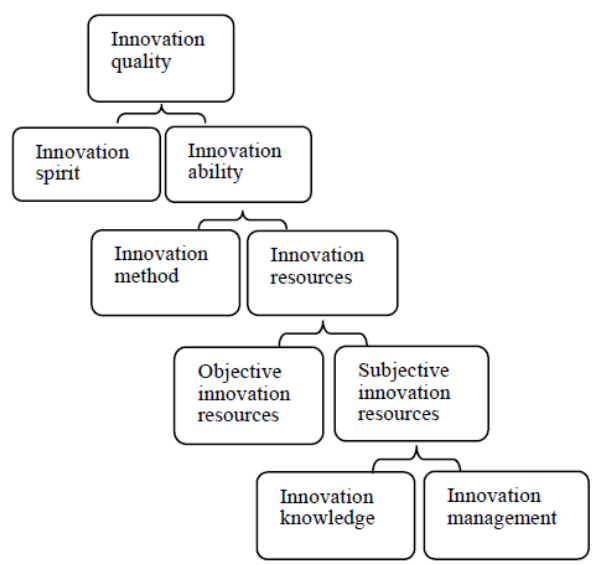

Fig. 1. Part of innovation quality system.

\section{Systematic MORAL EDUCATION INSPIRED}

The systematic contradiction of Marxist innovation education inspires a structure of systematic moral education for information age. Professor Huo Fuguang manifested that any person of morality must have innovation quality to solve problems; and predicted: with globalization, the information moral education must be based on information globalization, and enhance the universality of its standards, regulations, and its construction purposes, principals [6]. This is quite predictive, proved right already by our system-constructing, especially when the innovation resources were collected worldwide through the internet. The research of information moral education together with our practice inspired us to construct systematic moral education under the direction of Marxist innovation theory.

There is no need to say, that the information moral education is based on information globalization. But the problem is how to enhance the universality of the information moral education? 
We propose the deduction of the systematic contradiction of Marxist innovation education for its standards and regulations, and propose setting its construction purpose as to enhance the innovation quality, all should be under the principals of Marxist innovation theory. Then we can establish a systematic contradiction for innovation education by system-constructing. Because Marxism comes out of globalization, and has holistic philosophy for correct direction. And because Marxist innovation theory has been tested effective to construct systematic contradiction. Actually, systematic moral education could only be wholesome, when the innovation quality enhancement is considered, since the innovation quality is indispensable to morality. Professor Huo Fuguang might agree, that any student of morality must have innovation quality, such as innovation resources, without it, the education activity could not be able to realize the goal of moral education. Besides, if the innovation education become a field of systematic moral education, we can then enlarge the application of the requests of innovation quality by national education system. This would be a good arrangement for national innovation education. And then Marxist innovation education might be more constructive for the systematic moral education, because the innovation quality composes part of student's moral quality structure.

\section{CONCLUSION}

With the help of Marxist innovation theory, we constructed a market-oriented gadget for the automatic culture of Cordyceps militaris. The application of Marxist theory is obviously approved effective to problem analyzing and solving for innovation. Then this makes the above system displayed in fig. 1. essential factors to our consideration in the enhancement of innovation quality education. Marxist innovation education has been exemplified as the systematic contradiction of Marxist innovation practice education and Marxist innovation theory education. The former exists first, plays the decisive role, then is the principle aspect. And our practice inspired us that the systematic moral education should engage the innovation quality education, to reform moral education with innovation education systematically. And the innovation quality enhancement should be considered one of its purposes. What impressed us most is that, it is the innovation knowledge makes innovation wanted, processed and completed. Otherwise, when the innovation knowledge is absent, nobody can find the "week" or "missing" link of the innovation process, or can not even make a clear definition of the problems that play leading role. Only with adequate subjective resources, especially the innovation knowledge, can we obtain the indispensable software of innovation.

So, in the construction of the systematic moral education, we should consider innovation spirit and innovation ability, innovation method and innovation resources, innovation subjective resources and objective resources, innovation knowledge and innovation management. Each pair gives birth to detailed content through inner interaction of contradiction. And Marxist innovation practice education should be taken as the prerequisite of Marxist innovation theory education, must be able to afford enough opportunities for the practice of Marxist innovation method of combination, to strengthen the innovation resource education, especially the innovation knowledge that belongs to the subjective resources of innovation.

The researchers interested in relevant fields might need to consider the following questions:

1) Is it true that the innovation method of combination is always based on separation?

2) In terms of the systematic structure, in what circumstances will the latter function the principle aspect instead of the secondary aspect?

3) How to support Marxist systematic moral education by adequate innovation quality and evaluation in details?

\section{ACKNOWLEDGMENT}

Luo Qing thanks Zhaoqing University, for its scientific research fund project helped financially and for its research specialist staff, and in terms of marketing, thanks the cooperation of Guangdong Province Chaonengliang Industrial Co., Ltd.

\section{REFERENCES}

[1] L. Qing, "A research on the development of Marxist theory of innovation," Ph.D. dissertation, Dept. Marxism South China University of Technology, p. 137, 2012.

[2] H. John and C. Matt, "Medicinal value of the caterpillar fungi species of the genus Cordyceps (Fr.) link (Ascomycetes), a review," International Journal of Medicinal Mushrooms, vol. 10, no. 3, pp. 219-234, 2008.

[3] L. Qing, "The dialectic process of evaluation standards for education innovation," Advances in Social and Behavioral Sciences, pp.139-142, vol.1, 2013.

[4] L. Qing, "A research on the development of Marxist theory of innovation," The PhD. degree paper of South China University of Technology, p. 117, 2012

[5] N. X. Jian, "Business studies in theory and practice-the fundamentals of international business study," Microfilm and Copy Centre Ltd, 1999, p.112.

[6] H. Fuguang, "The theoretical thinking of Information moral education within Colleges and Universities," School Party Building and Ideological Education, p. 16, 2007.

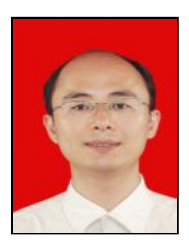

Qing Luo is teaching in the Department of Ideological and Political Theory, Zhaoqing University, Yingbin Road, Zhaoqing City, Guangdong, China. He is a PhD in major field of the sinicization of Marxist innovation theory, earned in 2012, School of Marxism at South China University of Technology, with undergraduate majored in English.

He is a moral instructor of basic principles of Marxism in Zhao Qing University, who has fellowship jobs as chairman of the science and technology association for Guangdong Province Chaoneng Industrial Co., Ltd. He worked as interpreter in several companies doing foreign trade, and worked as warehouse adimisnistrator in Taiwan Ming Enterprise Ltd., has the experience of superviser in Accelerated Education of Christianity. He is also the chain business entrepreneur of Cordyceps militaris in summer vacation at I Hua Lovely Family. The major book or articles published through internet are: A Research on the Development of Marxist Theory of Innovation (South China University of Technology: CNKI, 2012); The Analysis of the Innovation Function of NCE in Canada (Shanghai, China: IEEE 2011); The Dialectic Process of Evaluation Standards for Education Innovation (Saipan, USA: SSR 2013). His current interests are about innovation evaluation, education and systematic moral education based on the previous research of innovation theory.

Dr. Luo Qing, one assistant consultant of International Organization for Standardization(ISO), was honored Outstanding Paper Award by the Food Forum of College Dean in Guangdong Province, for an article "The cordyceps militaris breeding and culture method innovation conducted by the method of contradiction analysis," 